\title{
International practice variation in postoperative imaging of chronic subdural hematoma patients
}

\author{
Alexander F. C. Hulsbergen, BS,,2 Sandra C. Yan, BS, ${ }^{1}$ Brittany M. Stopa, MPH, ${ }^{1}$ \\ Aislyn DiRisio, BS, ${ }^{1}$ Joeky T. Senders, BS, ${ }^{1,2}$ Max J. van Essen, BS, ${ }^{2}$ \\ Stéphanie M. E. van der Burgt, MS, ${ }^{1,3}$ Timothy R. Smith, MD, PhD, MPH, ${ }^{1}$ \\ William B. Gormley, MD, MPH, MBA, ${ }^{1}$ and Marike L. D. Broekman, MD, PhD, JD ${ }^{1,2,4,5}$

\begin{abstract}
${ }^{1}$ Computational Neuroscience Outcomes Center (CNOC), Department of Neurosurgery, Brigham and Women's Hospital, Harvard Medical School, Boston, Massachusetts; '2Department of Neurosurgery, Rudolf Magnus Institute for Neuroscience, University Medical Center Utrecht; ${ }^{3}$ Department of Research in Education, VUMC School of Medical Sciences, Amsterdam,

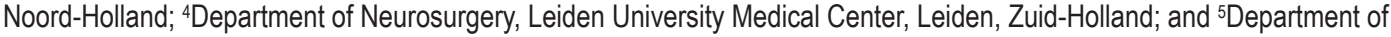
Neurosurgery, Haaglanden Medical Center, The Hague, The Netherlands
\end{abstract}

\begin{abstract}
OBJECTIVE The value of CT scanning after burr hole surgery in chronic subdural hematoma (CSDH) patients is unclear, and practice differs between countries. At the Brigham and Women's Hospital (BWH) in Boston, Massachusetts, neurosurgeons frequently order routine postoperative CT scans, while the University Medical Center Utrecht (UMCU) in the Netherlands does not have this policy. The aim of this study was to compare the use of postoperative CT scans in CSDH patients between these hospitals and to evaluate whether there are differences in clinical outcomes.

METHODS The authors collected data from both centers for 391 age- and sex-matched CSDH patients treated with burr hole surgery between January 1,2002, and July 1, 2016, and compared the number of postoperative scans up to 6 weeks after surgery, the need for re-intervention, and postoperative neurological condition.

RESULTS BWH patients were postoperatively scanned a median of 4 times (interquartile range [IQR] 2-5), whereas UMCU patients underwent a median of 0 scans (IQR $0-1, p<0.001)$. There was no significant difference in the number of re-operations ( 20 in the BWH vs 27 in the UMCU, $p=0.34$ ). All re-interventions were preceded by clinical decline and no recurrences were detected on scans performed on asymptomatic patients. Patients' neurological condition was not worse in the UMCU than in the BWH $(p=0.43)$.
\end{abstract}

CONCLUSIONS While BWH patients underwent more scans than UMCU patients, there were no differences in clinical outcomes. The results of this study suggest that there is little benefit to routine scanning in asymptomatic patients who have undergone surgical treatment of uncomplicated CSDH and highlight opportunities to make practice more efficient. https://thejns.org/doi/abs/10.3171/2018.8.JNS181767

KEYWORDS chronic subdural hematoma; burr hole craniotomy; chronic subdural hematoma; computed tomography; $\mathrm{CT}$; practice variation; recurrence; trauma

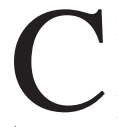

HRONIC subdural hematoma (CSDH) is a neurosurgical condition especially prevalent among elderly patients. ${ }^{1,12,39}$ Increasing incidence of CSDH due to an aging population underlines the need for evidencebased treatment protocols. ${ }^{10,32}$ Current clinical management is not standardized and is therefore subject to practice variation on an inter-surgeon, national, and international level. $2,4,8,27,33$
Computed tomography (CT) is used postoperatively to monitor hematoma recurrence, the most common complication of a CSDH. ${ }^{10,41}$ Definitions given for recurrence vary, but the simplest describes re-accumulation of blood in the hematoma cavity concurrent with re-appearance of neurological symptoms. ${ }^{24}$ Due to a lack of robust evidence on what is the best postoperative imaging policy, practices vary between institutions and individual sur-

ABBREVIATIONS BWH = Brigham and Women's Hospital; CSDH = chronic subdural hematoma; $\mathrm{CT}=$ computed tomography; IQR = interquartile range; UMCU = University Medical Center Utrecht.

SUBMITTED June 19, 2018. ACCEPTED August 9, 2018.

INCLUDE WHEN CITING Published online December 21, 2018; DOI: 10.3171/2018.8.JNS181767. 
geons. ${ }^{9,39,41}$ On an institutional level, practices vary from performing no routine $\mathrm{CT}$ scan and only clinical monitoring of neurological symptoms to performing as many as 4 routine scans in the first 3 months after surgery. 22,29,30,40,43 Surveys carried out in the United Kingdom, Ireland, and France indicate that between one-third and two-thirds of surgeons order routine scans. ${ }^{27,33}$ Systematic scanning of all CSDH patients has been recommended by one study, since certain radiological findings, such as the persistence of midline shift, have been found to predict hematoma recurrence..$^{10}$ However, it remains to be elucidated whether routinely performed postoperative CTs lead to direct clinical implications, such as re-interventions, faster response to hematoma recurrence, and better patient outcomes.

The aim of this study was to compare postoperative CT scanning policies in the management of CSDH between 2 hospitals - one in Boston, Massachusetts, and the other in Utrecht, the Netherlands. Additionally, we assessed whether one of the policies leads to better CSDH recurrence detection and better clinical outcome.

\section{Methods \\ Data Source}

Data were collected from the electronic health records of 2 large, academic, tertiary hospitals: the Brigham and Women's Hospital (BWH) in Boston, Massachusetts, and the University Medical Center Utrecht (UMCU) in the Netherlands. At the BWH, multiple CT scans are routinely obtained postoperatively as a primary means of evaluating patient recovery. Although there is no formal policy recommending the number and timing, scans are obtained both immediately after surgery and during outpatient follow-up. At the UMCU, patients are only monitored clinically, and a CT scan is ordered if neurological symptoms appear. For our analysis, we selected 2 cohorts of patients who were all treated for a CSDH by means of burr hole craniotomy between 2002 and 2016. Burr hole craniotomy in both centers consists of the placing of two 14-mm drilled holes in the skull and subsequent opening of the dura. One hole is used for hematoma evacuation, while the other is used as an entry port for irrigation. $\mathrm{Pa}-$ tients treated with twist drill surgeries, craniotomies, and mini-craniotomies were excluded. The cohort from BWH consisted of 196 consecutive patients; this constituted around $97 \%$ of treated patients, as 6 cases lacked sufficient data for inclusion. In the UMCU, 195 patients were selected to match by sex and age where possible; this represented around $31 \%$ of available cases. This difference in available cases stems from the fact that all CSDH surgeries in the UMCU are burr hole craniotomies, while BWH surgeons also use other techniques. In the BWH, approval for data collection was acquired from the Partners Human Research Committee. In the UMCU, the hospital's medical ethics committee stated that the rules of the Dutch Medical Research on Human Subjects Act did not apply to this study.

\section{Variables}

The following data points were collected for each patient: age, sex, use and type of anticoagulation, laterality of hematoma and surgery, use of drains, length of hospital stay, postoperative seizures, and postoperative head traumas. Data about the need and indication for re-operation within 6 months were collected as the primary outcome measure. Secondary outcome measures were neurological outcome at discharge and at 6 weeks' follow-up. These outcomes were classified as stabilized or worsened compared to their pre-disease state. Stabilized patients were those who had not neurologically deteriorated at discharge or follow-up as assessed by Glasgow Coma Scale and neurological physical examination as documented in patient records. Patients whose condition had deteriorated were considered worsened. If a patient had multiple recurrences, only the first recurrence was analyzed.

\section{Statistical Analysis}

Data were analyzed using R (version 3.2.1). Categorical variables were described using counts and percentages, while continuous variables were expressed using mean, median, range, and interquartile range. In case of loss to follow-up, outcomes were expressed as percentages of the patients for whom follow-up data were available. In the baseline and outcomes analyses, categorical variables were compared with the chi-square and Fisher's exact tests and continuous variables with parametric distribution with the Student t-test. The Mann-Whitney Utest was used to explore the difference in number of CT scans between the cohorts. Logistic regression was used to determine whether the number of re-operations differed by hospital. Any value of $\mathrm{p}$ below 0.05 was determined significant.

\section{Results \\ Demographics of the Study Population}

In the 391 cases analyzed, the male-to-female ratio was 69:31. The median age was 74 years in the BWH and 75.5 years in the UMCU. One hundred thirty-seven hematomas were left-sided, 127 were right-sided, and 127 were bilateral. One hundred ninety-two patients (49\%) were on anticoagulant drugs at presentation. Other baseline characteristics are presented for all patients in Table 1, compared by institution. Overall, there were no significant differences between the cohorts in age, sex, side of surgery, or total use of anticoagulant drugs.

\section{Postoperative Course}

Differences in postoperative course between our cohorts are outlined in Table 2. In the BWH, 193 patients (99\%) received at least 1 CT scan postoperatively, whereas 86 (44\%) of the Dutch patients did. Patients from the BWH cohort had a mean of 3.9 and a median of 4 (interquartile range [IQR] 3-5) postoperative CT scans, while patients from the Netherlands had a mean of 0.8 and a median of 0 (IQR $0-1, \mathrm{p}<0.001$ ); this constitutes a 5 -fold difference. Figure 1 outlines the distribution of $\mathrm{CT}$ scans per patient in both institutions.

In the BWH, the first postoperative scan was most often without a direct clinical indication recorded in the radiology report $(\mathrm{n}=163)$. Other indications included neurological deterioration $(n=16)$, headache $(n=10)$, seizure $(n=$ 
TABLE 1. Baseline characteristics of CSDH patients at BWH and UMCU

\begin{tabular}{lcccc}
\hline \multicolumn{1}{c}{ Characteristic } & BWH $(\mathrm{n}=196)$ & UMCU $(\mathrm{n}=195)$ & Total $(\mathrm{n}=391)$ & $\mathrm{p}$ Value \\
\hline Median age in yrs (range) & $74(21-95)$ & $75(33-98)$ & $75(21-98)$ & NA \\
\hline Male & $141(71.9)$ & $130(66.7)$ & $271(69.3)$ & NA \\
\hline Side of hematoma & & & $137(35)$ & $>0.99$ \\
\hline Left & $69(35.2)$ & $68(34.9)$ & $127(32.5)$ & 0.02 \\
\hline Right & $52(26.5)$ & $75(38.5)$ & $127(32.5)$ & 0.02 \\
\hline Bilateral & $75(38.3)$ & $52(26.7)$ & & $>0.99$ \\
\hline Side of surgery & & & $152(38.9)$ & 0.73 \\
\hline Left & $76(38.8)$ & $76(39)$ & $150(38.4)$ & 0.65 \\
\hline Right & $73(37.2)$ & $77(39.5)$ & $89(22.8)$ & 0.80 \\
\hline Bilateral & $47(24)$ & $42(21.5)$ & $107(27.4)$ & 0.13 \\
\hline Anticlotting Tx & & $31(7.9)$ & 0.20 \\
\hline Aspirin & $52(26.7)$ & $55(28.2)$ & $30(7.6)$ & 0.20 \\
\hline Heparin & $8(4.1)$ & $23(11.8)$ & $126(32.2)$ & 0.50 \\
\hline Clopidogrel & $7(3.6)$ & $23(11.8)$ & $1(0.3)$ & 0.31 \\
\hline Vitamin K inhibitors & $56(28.6)$ & $70(35.9)$ & $192(49.5)$ & \\
\hline Novel anticoagulants & $0(0.0)$ & $1(0.5)$ & $90(46.6)$ & \\
\hline Total & $102(52.3)$ & & & \\
\hline
\end{tabular}

$\mathrm{NA}=$ not applicable; $\mathrm{Tx}=$ therapy.

Data are numbers of patients (\%) unless otherwise indicated.

1), and unknown reasons due to unavailable information $(n=4)$. In the UMCU cohort, scanning was performed in 42 cases without a recorded clinical indication, in 30 due to diminishing neurological function, in 5 due to seizure, in 2 due to suspicion of infection, in 4 due to headache, and in 1 case for unknown reasons. Figure 2 provides an overview of indications for the first scan.

Drains were used more often in the UMCU cohort (in $85 \%$ vs $76 \%$ of patients, $p=0.006$ ). Hospital length of stay was slightly shorter in the UMCU (median 5 days [IQR 4-6] vs median 5 days [IQR 4-9] in the BWH, $\mathrm{p}=0.05$ ).
Head traumas were recorded more often in the BWH cohort ( 13 cases vs 1 case, $p=0.002$ ).

\section{Clinical Outcomes}

Forty-seven patients (12\%) needed re-operation due to hematoma recurrence. There were 20 re-operations in the BWH $(10 \%)$ as compared to 27 in the UMCU $(14 \%, \mathrm{p}=$ $0.27)$. This difference remained non-significant after correcting for postoperative drains $(\mathrm{p}=0.34)$. No re-operations were performed based on results of routine $\mathrm{CT}$ scans in asymptomatic patients. Patients had either clinical dete-

TABLE 2. Postoperative results

\begin{tabular}{lcccc}
\hline \multicolumn{1}{c}{ Characteristic } & BWH $(\mathrm{n}=196)$ & UMCU $(\mathrm{n}=195)$ & Total $(\mathrm{n}=391)$ & $\mathrm{p}$ Value \\
\hline Pts receiving at least 1 postop scan & $193(98.5)$ & $86(44.1)$ & $279(71.4)$ & $<0.001$ \\
\hline Median no. of CT scans per pt (IQR) & $4(2-5)$ & $0(0-1)$ & $2(0-4)$ & $<0.001$ \\
\hline Pts w/ drains & $148(75.9)$ & $166(85.1)$ & $314(80.3)$ & 0.006 \\
\hline Postop head trauma & $13(7.3)$ & $1(0.5)$ & $14(3.8)$ & 0.002 \\
\hline Postop seizures & $14(7.8)$ & $7(3.6)$ & $21(5.6)$ & 0.12 \\
\hline Re-operated pts & $20(10.2)$ & $27(13.8)$ & $47(12)$ & 0.34 \\
\hline Median LOS in days (IQR) & $5(4-9)$ & $5(4-6)$ & $5(4-7)$ & 0.05 \\
\hline Neuro condition at discharge & & & $355(93.7)$ & 0.001 \\
\hline Stabilized & $166(89.2)$ & $189(97.9)$ & $24(6.3)$ & 0.001 \\
\hline Worsened & $20(10.8)$ & $4(2.1)$ & & \\
\hline Neuro condition at 6 wks FU & & & & 0.43 \\
\hline Stabilized & $139(84.2)$ & $91(79.8)$ & $230(82.4)$ & 0.43 \\
\hline Worsened & $26(15.8)$ & $23(20.2)$ & $49(17.6)$ & \\
\hline
\end{tabular}

$\mathrm{FU}=$ follow-up; $\mathrm{IQR}$ = interquartile range; $\mathrm{LOS}=$ length of hospital stay; neuro = neurological; $\mathrm{pt}$ = patient.

Data are numbers of patients (\%) unless otherwise indicated. 


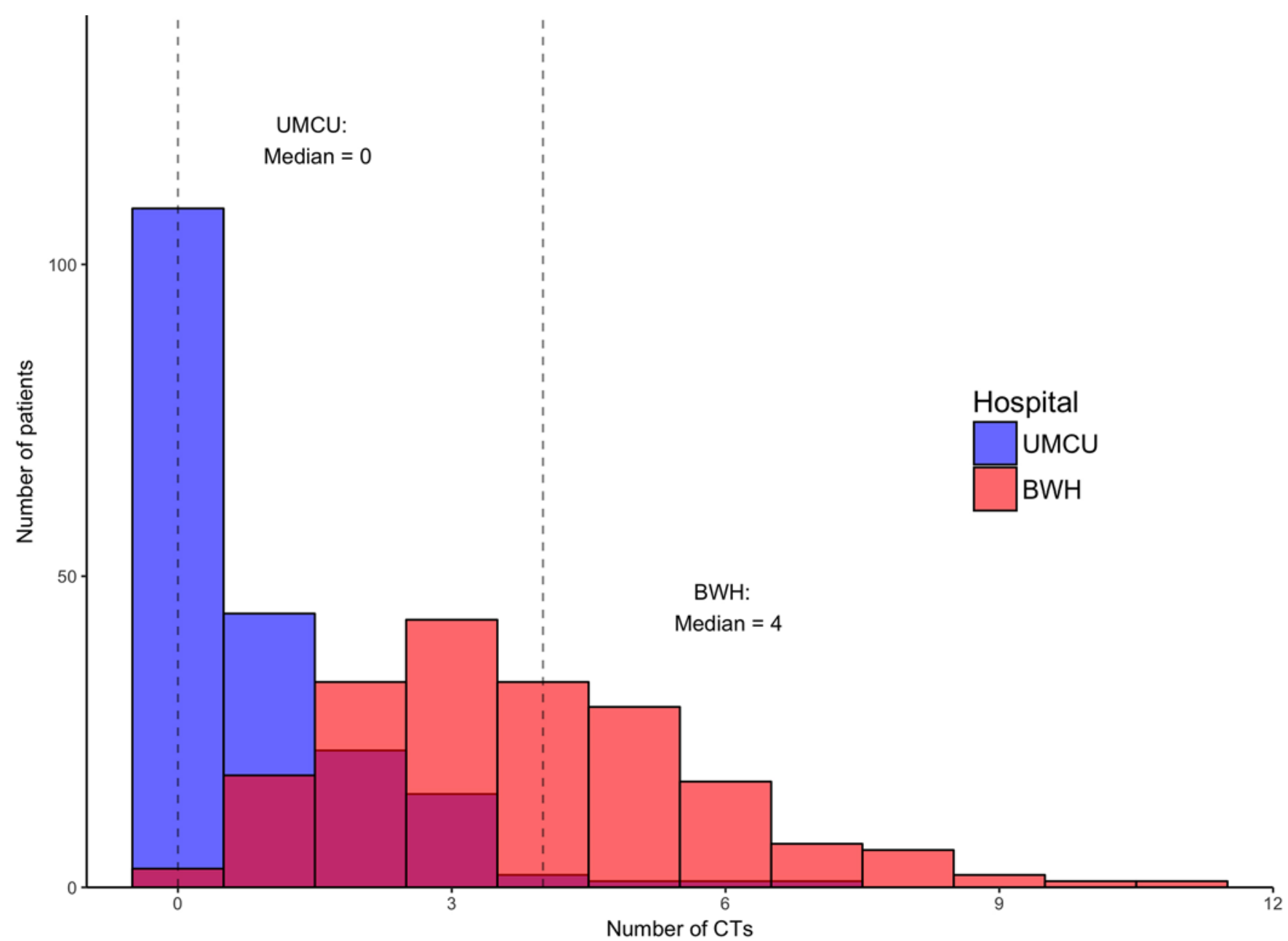

FIG. 1. Distribution of number of postoperative CT scans per patient. Patients received a median of 0 postoperative scans in the UMCU versus 4 in the BWH $(p<0.001)$. Figure is available in color online only.

rioration $(n=46)$ or progressively worsening international normalized ratio (INR) values despite intensive treatment $(\mathrm{n}=1)$, which prompted concern for recurrence.

For secondary outcome analysis, neurological conditions at discharge were available for 379 patients. At discharge, $166 \mathrm{BWH}$ patients (89\%) and 189 UMCU patients $(98 \%)$ were stabilized $(\mathrm{p}=0.001)$. Among patients who had documented neurological assessments at 6 weeks (n = 279), 139 BWH patients $(84 \%)$ and $91 \mathrm{UMCU}$ patients $(80 \%)$ were stabilized $(\mathrm{p}=0.43$, Table 2$)$.

\section{Discussion}

Our results indicate a considerable disparity in the postoperative management of CSDH patients between the BWH and UMCU cohorts: the rate of CT scanning was 5 times higher in the BWH cohort. Nevertheless, there was no significant difference in the rate of re-interventions, and in both hospitals, all patients who underwent re-operation showed prior signs of clinical decline. No recurrence was detected on scans that were performed on asymptomatic patients. Moreover, UMCU patients who were conser- vatively managed did not have worse clinical outcomes. It therefore appears that scanning asymptomatic patients does not lead to a higher rate of recurrence detection.

To our knowledge, this is the first multicenter comparison of patient outcomes in relation to postoperative scanning policies in a neurosurgical setting.

Several studies have investigated the use of routine postoperative CT scanning in neurosurgical indications. In line with our findings, a retrospective analysis of a series of 202 Danish SDH patients performed by Pedersen et al. showed no benefit to a CT scan 6 weeks after surgery. ${ }^{26}$ Garrett et al. (2013) ${ }^{13}$ examined 126 routine postoperative head CT scans in various pathologies and found that only 6 yielded a clinically significant finding, and only 1 of these 6 ( $0.8 \%$ of the overall group) resulted in re-intervention. Khaldi et al. $(2010)^{18}$ found that $0 \%$ of 251 patients returned to the operating room due to findings of routine CT scans obtained within 24 hours after cranial surgery without new neurological findings, compared to $30 \%$ who had CT findings after neurological symptoms had appeared. Schär et al. (2016) 34 demonstrated in a cohort of 492 patients who had undergone elective craniotomy that routine 


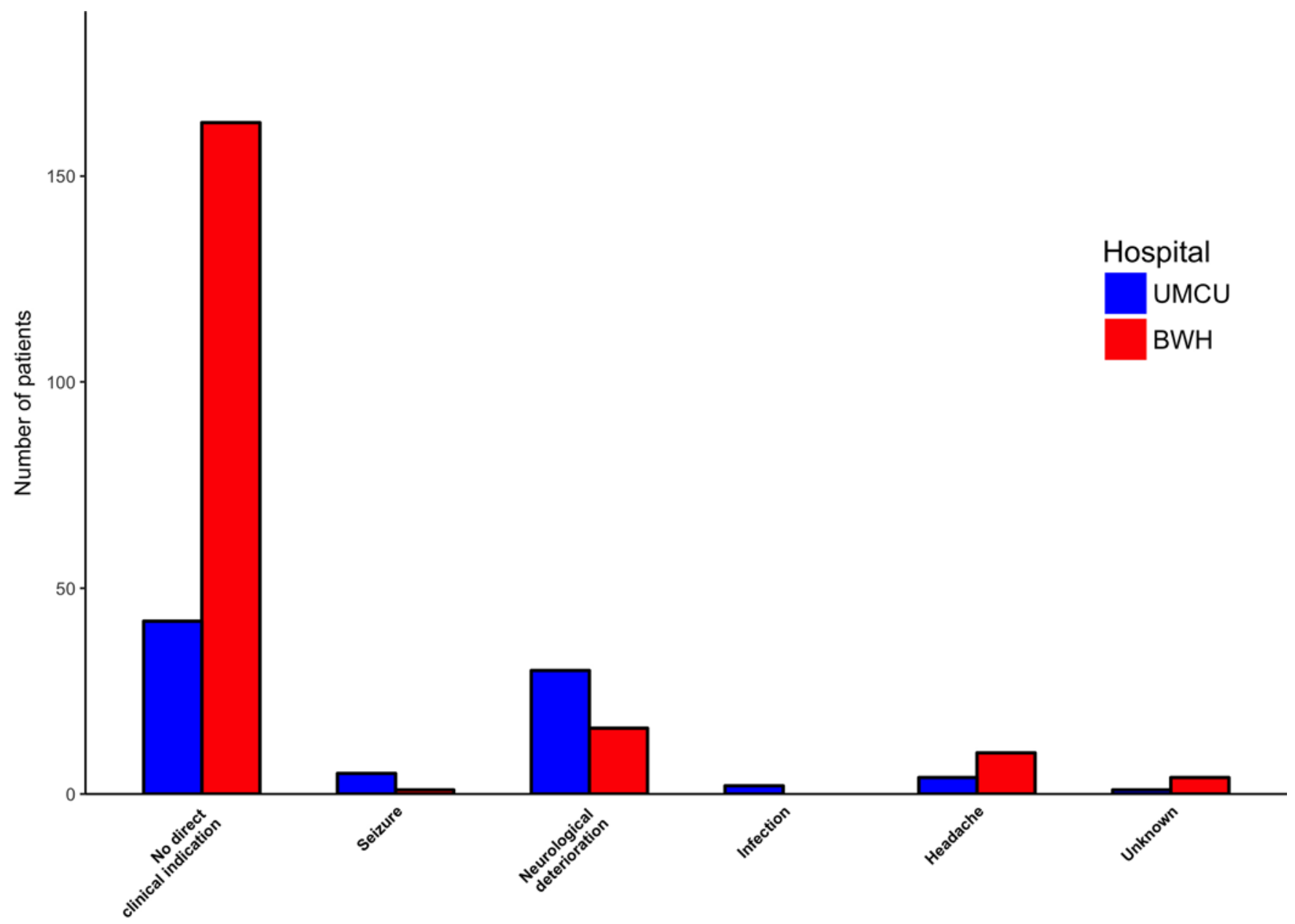

FIG. 2. Indications for the first postoperative CT scan per hospital. Figure is available in color online only.

postoperative CT scanning was not necessary as long as the patient was extubated within an hour after surgery and his or her neurological condition was closely monitored. Moreover, authors of different studies in oncological and skull base tumor surgery, $, 3,14,18,22$ spinal surgery, ${ }^{15}$ and pediatric cranial reconstruction ${ }^{5}$ have concluded that routine scanning has little clinical impact if surgery was without complications and can usually be omitted in the absence of neurological or other symptoms.

In the setting of mild traumatic brain injury, a systematic review of 19 studies by Stippler et al. (2012) (38 $^{38}$ concluded that routine CT scans do not predict the need for neurosurgical intervention, and rarely alter treatment. While none of these indications can be compared to CSDH directly, the studies suggest that while routine CT scans are widely used in neurosurgery, they could often be safely omitted in favor of clinical monitoring of symptoms. The results of the present study are consistent with these findings.

The practice variation we reported parallels the international variety in use of CT scans for all indications. CT imaging plays a major diagnostic role in the US, where around 65 million scans are obtained in adults annually. ${ }^{6}$ In 2009, an average of 228 exams per 1000 individuals in the population were performed, which is more than 3 times as many as in the Netherlands (66 per 1000), and still a higher rate than in other developed countries, such as Canada (125 per 1000) or France (139 per 1000). ${ }^{37}$

Drains were used slightly more often in the UMCU ( $85 \%$ vs $76 \%$ ). There is some evidence that postoperative drains lower the number of symptomatic recurrences in $\mathrm{CSDH} .{ }^{28}$ However, in our cohort, drain usage was not predictive for re-intervention (data not shown), and there was no significant difference in number of re-operations between hospitals even after correcting for postoperative drain usage.

Interestingly, even in the UMCU, 42 of 195 patients received postoperative CT scans without a recorded clinical indication. This may indicate that even though there is a policy of not ordering CT scans unless clinically indicated, not all physicians adhere to this policy.

\section{Limitations and Strengths}

The retrospective nature of our study warrants some cautions. We did not standardize a routine CT policy in the BWH for this comparison. This could have created an ideal research setting; however, our aim was rather to 
compare real-time clinical practice in the 2 institutions. Likewise, the patients in our analysis were not randomized between management strategies; prospective randomization would eliminate the risk of unknown confounding variables. Our 6 months of follow-up for re-operations was quite extensive. Still, there is a possibility that some patients experienced SDH recurrence after this time and were therefore missed in our analysis. For our secondary outcomes analysis, 6-week neurological checks were not available for all patients; some uncomplicated patients would have been followed at a local clinic rather than in the academic hospital. All patients did have 6-month reoperation outcome data available. Moreover, patients who were neurologically worsened at discharge or were in need of re-operation all had neurological 6-week follow-up data available. Lastly, burr hole evacuation is not the most commonly used operative technique for $\mathrm{CSDH}$ in the BWH. The goal of this study was, however, not to determine the relative value of one operative approach over another, but to determine the role of routine CT scans in the management of patients undergoing surgery for CSDH.

The strengths of our study include a large age- and sex-matched sample size from high-volume neurosurgical practices at tertiary academic medical centers with considerable experience in postoperative CSDH management.

\section{Implications}

The direct implication if one were to generalize our results is that there is no difference in outcomes between CSDH patients in the US and similar patients in the Netherlands, where there is a sharply reduced use of postoperative CT scanning. This practice variation could have multiple reasons, and our goal is to identify areas in which it can be reduced without patient harm.

There is some evidence that the differences in medicolegal climate and associated defensive practices could play a role. Defensive medicine, under the most common definition proposed by the US Congress Office of Technology Assessment (OTA), occurs "when doctors order tests, procedures, or visits, or avoid certain high-risk patients or procedures, primarily (but not solely) because of concern about malpractice liability." ${ }^{23}$ In the present study, this could mean ordering extra CT scans to prevent patients' lawsuits over missed findings. Defensive behaviors vary geographically, with neurosurgeons in areas with unfavorable liability climates practicing more defensively. ${ }^{7,35,36,42}$ The Dutch medicolegal climate is very different from the American one. Most notably, it is uncommon for patients to sue their physicians in the Netherlands, and Dutch neurosurgeons experience little burden from lawsuits or liability premiums. ${ }^{42}$ These remarkable differences are likely to play some role in the differences in utilization of diagnostic tests, which we report in our study.

A second factor in this practice variance may be rooted in how culturally appropriate patient expectations might influence practice. In the American healthcare system, physicians compete for patients and are regularly subjected to assessment by patient satisfaction-based metrics. This may result in a higher tendency toward patient satisfaction versus strict necessity of procedures. Patients could perceive lack of regular scanning as improper care ${ }^{11,16,20,31}$ and switch surgeons, which would have direct financial consequences for involved caregivers. This is different in most European healthcare systems, including the Dutch one, where most doctors do not compete for cases and are paid a fixed salary independent of their patient volume.

The third and, in our minds, most significant variance is that in the American medical system, the culture among caregivers is to avoid patient harm at all cost, with little consideration for cost-effectiveness of indications. It is not surprising, given these cultural differences, that the cost of American healthcare is higher than that of healthcare in comparable developed countries without delivering significantly different outcomes. ${ }^{37}$ Caregivers have very few constraints on their capacity to order any procedure they deem necessary, without cost concerns and often with little evidence-based data to support these decisions. In the Netherlands, on the other hand, virtually all neurosurgical care is publicly funded; there is a heavy emphasis and control of the ordering of procedures based on evidence, which is often a requirement for reimbursement. ${ }^{19}$

\section{Opportunities}

Understanding the factors that contribute to practice variation in postoperative imaging can help identify opportunities to make practice more efficient and cost-effective. In the example of our study, a 5-fold difference in CT scans, which on average cost $\$ 1390$ per scan in US academic hospitals, ${ }^{25}$ would imply a potential $\$ 817,000$ savings in this specific type of surgery within a single institution, with no disadvantages for patient outcomes. It is possible that with the dissemination of comparative data such as ours, progress can be made in developing best practices by reducing variances in care.

\section{Conclusions}

Our study found considerable practice variation in postoperative CT scanning of CSDH patients, but did not show any differences in patient outcomes that suggest a benefit to routine scanning. Our results suggest that routine postoperative scanning has no added value in asymptomatic patients who have undergone surgical treatment of uncomplicated CSDH and suggest future investigation into opportunities to cut unnecessary imaging procedures in this patient population and potentially in other treatment groups.

\section{References}

1. Adhiyaman V, Asghar M, Ganeshram KN, Bhowmick BK: Chronic subdural haematoma in the elderly. Postgrad Med J 78:71-75, 2002

2. Avanali R, Bhadran B, Krishna Kumar P, Vijayan A, Arun S, Musthafa AM, et al: Chronic subdural hematoma: a questionnaire survey of management practice in India and review of literature. World Neurosurg 96:355-361, 2016

3. Benveniste RJ, Ferraro N, Tsimpas A: Yield and utility of routine postoperative imaging after resection of brain metastases. J Neurooncol 118:363-367, 2014

4. Berghauser Pont LM, Dippel DW, Verweij BH, Dirven CM, Dammers R: Ambivalence among neurologists and neurosurgeons on the treatment of chronic subdural hematoma: a national survey. Acta Neurol Belg 113:55-59, 2013 
5. Binning M, Ragel B, Brockmeyer DL, Walker ML, Kestle JR: Evaluation of the necessity of postoperative imaging after craniosynostosis surgery. J Neurosurg 107 (1 Suppl):43-45, 2007

6. Brenner DJ: Should we be concerned about the rapid increase in CT usage? Rev Environ Health 25:63-68, 2010

7. Carrier ER, Reschovsky JD, Katz DA, Mello MM: High physician concern about malpractice risk predicts more aggressive diagnostic testing in office-based practice. Health Aff (Millwood) 32:1383-1391, 2013

8. Cenic A, Bhandari M, Reddy K: Management of chronic subdural hematoma: a national survey and literature review. Can J Neurol Sci 32:501-506, 2005

9. Ducruet AF, Grobelny BT, Zacharia BE, Hickman ZL, DeRosa PL, Andersen KN, et al: The surgical management of chronic subdural hematoma. Neurosurg Rev 35:155-169, 2012 (Erratum in Neurosurg Rev 38:771, 2015)

10. Dudoit T, Labeyrie PE, Deryckere S, Emery E, Gaberel T: Is systematic post-operative $\mathrm{CT}$ scan indicated after chronic subdural hematoma surgery? A case-control study. Acta Neurochir (Wien) 158:1241-1246, 2016

11. Engel GL: The need for a new medical model: a challenge for biomedicine. Science 196:129-136, 1977

12. Foelholm R, Waltimo O: Epidemiology of chronic subdural haematoma. Acta Neurochir (Wien) 32:247-250, 1975

13. Garrett MC, Bilgin-Freiert A, Bartels C, Everson R, Afsarmanesh N, Pouratian N: An evidence-based approach to the efficient use of computed tomography imaging in the neurosurgical patient. Neurosurgery 73:209-216, 2013

14. Geßler F, Dützmann S, Quick J, Tizi K, Voigt MA, Mutlak $\mathrm{H}$, et al: Is postoperative imaging mandatory after meningioma removal? Results of a prospective study. PLoS One 10:e0124534, 2015

15. Halevi PD, Udayakumaran S, Ben-Sira L, Constantini S: The value of postoperative MR in tethered cord: a review of 140 cases. Childs Nerv Syst 27:2159-2162, 2011

16. Ioannidis JP, Prasad V: Evaluating health system processes with randomized controlled trials. JAMA Intern Med 173:1279-1280, 2013

17. Jiang ZY, Allen K, Kutz JW Jr, Isaacson B: Clinical impact of early CT scans after lateral skull-base surgery. Otolaryngol Head Neck Surg 149:786-788, 2013

18. Khaldi A, Prabhu VC, Anderson DE, Origitano TC: The clinical significance and optimal timing of postoperative computed tomography following cranial surgery. J Neurosurg 113:1021-1025, 2010

19. Kroneman M, Boerma W, van den Berg M, Groenewegen P, de Jong J, van Ginneken E: Netherlands: health system review. Health Syst Transit 18:1-240, 2016

20. Macleod MR, Michie S, Roberts I, Dirnagl U, Chalmers I, Ioannidis JP, et al: Biomedical research: increasing value, reducing waste. Lancet 383:101-104, 2014

21. Nadimi S, Caballero N, Carpenter P, Sowa L, Cunningham $\mathrm{R}$, Welch KC: Immediate postoperative imaging after uncomplicated endoscopic approach to the anterior skull base: is it necessary? Int Forum Allergy Rhinol 4:1024-1029, 2014

22. Nakaguchi H, Tanishima T, Yoshimasu N: Relationship between drainage catheter location and postoperative recurrence of chronic subdural hematoma after burr-hole irrigation and closed-system drainage. J Neurosurg 93:791-795, 2000

23. Office of Technology Assessment: Defensive Medicine and Medical Malpractice, OTA-H--602. Washington, DC: U.S. Government Printing Office, 1994

24. Oh HJ, Lee KS, Shim JJ, Yoon SM, Yun IG, Bae HG: Postoperative course and recurrence of chronic subdural hematoma. J Korean Neurosurg Soc 48:518-523, 2010

25. Paul AB, Oklu R, Saini S, Prabhakar AM: How much is that head CT? Price transparency and variability in radiology. J Am Coll Radiol 12:453-457, 2015

26. Pedersen CB, Sundbye F, Poulsen FR: No value of routine brain computed tomography 6 weeks after evacuation of chronic subdural hematoma. Surg J (N Y) 3:e174-e176, 2017

27. Pencalet P: [Clinical forms and prognostic factors of chronic subdural hematoma in the adult.] Neurochirurgie 47:469472, 2001 (Fr)

28. Peng D, Zhu Y: External drains versus no drains after burr-hole evacuation for the treatment of chronic subdural haematoma in adults. Cochrane Database Syst Rev (8):CD011402, 2016

29. Ro HW, Park SK, Jang DK, Yoon WS, Jang KS, Han YM: Preoperative predictive factors for surgical and functional outcomes in chronic subdural hematoma. Acta Neurochir (Wien) 158:135-139, 2016

30. Rovlias A, Theodoropoulos S, Papoutsakis D: Chronic subdural hematoma: Surgical management and outcome in 986 cases: a classification and regression tree approach. Surg Neurol Int 6:127, 2015

31. Saini V, Garcia-Armesto S, Klemperer D, Paris V, Elshaug AG, Brownlee $S$, et al: Drivers of poor medical care. Lancet 390:178-190, 2017

32. Santarius T, Hutchinson PJ: Chronic subdural haematoma: time to rationalize treatment? Br J Neurosurg 18:328-332, 2004

33. Santarius T, Lawton R, Kirkpatrick PJ, Hutchinson PJ: The management of primary chronic subdural haematoma: a questionnaire survey of practice in the United Kingdom and the Republic of Ireland. Br J Neurosurg 22:529-534, 2008

34. Schär RT, Fiechter M, Z'Graggen WJ, Söll N, Krejci V, Wiest $\mathrm{R}$, et al: No routine postoperative head CT following elective craniotomy-a paradigm shift? PLoS One 11:e0153499, 2016

35. Smith TR, Habib A, Rosenow JM, Nahed BV, Babu MA, Cybulski G, et al: Defensive medicine in neurosurgery: does state-level liability risk matter? Neurosurgery 76:105-114, 2015

36. Smith TR, Hulou MM, Yan SC, Cote DJ, Nahed BV, Babu MA, et al: Defensive medicine in neurosurgery: the Canadian experience. J Neurosurg 124:1524-1530, 2016

37. Squires DA: Explaining high health care spending in the United States: an international comparison of supply, utilization, prices, and quality. Issue Brief (Commonw Fund) 10:1-14, 2012

38. Stippler M, Smith C, McLean AR, Carlson A, Morley S, Murray-Krezan C, et al: Utility of routine follow-up head CT scanning after mild traumatic brain injury: a systematic review of the literature. Emerg Med J 29:528-532, 2012

39. Teles AR, Falavigna A, Kraemer J: Surgical treatment of chronic subdural hematoma: systematic review and meta-analysis of the literature. Arq Bras Neurocir 35:118-127, 2016

40. Wada M, Yamakami I, Higuchi Y, Tanaka M, Suda S, Ono $\mathrm{J}$, et al: Influence of antiplatelet therapy on postoperative recurrence of chronic subdural hematoma: a multicenter retrospective study in 719 patients. Clin Neurol Neurosurg 120:49-54, 2014

41. Weigel R, Schmiedek P, Krauss JK: Outcome of contemporary surgery for chronic subdural haematoma: evidence based review. J Neurol Neurosurg Psychiatry 74:937-943, 2003

42. Yan SC, Hulsbergen AFC, Muskens IS, van Dam M, Gormley WB, Broekman MLD, et al: Defensive medicine among neurosurgeons in the Netherlands: a national survey. Acta Neurochir (Wien) 159:2341-2350, 2017

43. Yu GJ, Han CZ, Zhang M, Zhuang HT, Jiang YG: Prolonged drainage reduces the recurrence of chronic subdural hematoma. Br J Neurosurg 23:606-611, 2009

\section{Disclosures}

The authors report no conflict of interest concerning the materi- 
als or methods used in this study or the findings specified in this paper.

\section{Author Contributions}

Conception and design: Broekman, Hulsbergen, Yan, Senders. Acquisition of data: Hulsbergen, Yan, Stopa, DiRisio, van Essen. Analysis and interpretation of data: Hulsbergen. Drafting the article: Hulsbergen. Critically revising the article: all authors. Approved the final version of the manuscript on behalf of all authors: Broekman. Statistical analysis: Hulsbergen. Study supervision: Broekman, Smith, Gormley.

\section{Supplemental Information}

Previous Presentations

Preliminary data from this study were presented in electronic poster format at the 2017 Annual Scientific Meeting of the
American Association of Neurological Surgeons, April 22-26, in Los Angeles, California. Portions of this work have been presented in oral form at the 2018 Annual Meeting of the European Association of Neurological Societies, October 21-25, in Brussels, Belgium, and the 2018 Annual Meeting of the New England Neurosurgical Society, June 28-30, in Chatham, Massachusetts.

\section{Correspondence}

Marike L. D. Broekman: Leiden University Medical Center, Leiden University, Leiden, The Netherlands. marikebroekman@ gmail.com. 